\title{
Geographical origin discrimination of "Ntopia" olive oil cultivar from lonian islands using volatile compounds analysis and computational statistics
}

\author{
Effimia Eriotou ${ }^{1} \cdot$ loannis K. Karabagias ${ }^{2,3} \cdot$ Sofia Maina ${ }^{1,4} \cdot$ Dionysios Koulougliotis $^{5} \cdot$ Nikolaos Kopsahelis $^{1}$ (D)
}

Received: 8 July 2021 / Revised: 2 September 2021 / Accepted: 4 September 2021 / Published online: 20 September 2021

(c) The Author(s), under exclusive licence to Springer-Verlag GmbH Germany, part of Springer Nature 2021

\begin{abstract}
The aim of the present study was to characterize the aroma profile of olive oil of the "Ntopia" (local) cultivar from the Ionian islands (Zakynthos, Kefalonia, Leukada, and Kerkyra) (Greece), and investigate whether specific volatile compounds could be considered as indicators of olive oil geographical origin, using computational statistics. In this context, 137 olive oil samples were subjected to headspace solid phase microextraction coupled to gas chromatography/mass spectrometry using the internal standard method. Computational statistics on the semi-quantitative data of olive oil samples, as rapid machine learning algorithms, showed that specific volatile compounds could be used as indicators of geographical origin of olive oil of the "Ntopia" cultivar, among the four main Ionian islands. Volatile compounds such as ethanol, pentanal, 2,4-dimethylheptane, 3,7-dimethyl-1,3,6-octatriene (E), 2,5-dimethylnonane, 1-hexanol, 6-methyl-5-hepten-2-one, octanal, dl-Limonene, acetic acid hexyl ester and dodecane could aid to the geographical origin discrimination of "Ntopia" olive oil cultivar when two (Zakynthos and Kefalonia) or four (Zakynthos, Kefalonia, Leukada and Kerkyra) Ionian islands are subjected to statistical analysis. The discrimination rate using the cross-validation method was $100 \%$ and $85.7 \%$, respectively. These results were further evaluated using training and holdout partitions, during which a comparable classification rate was obtained.
\end{abstract}

Keywords Olive oil · "Ntopia" cv. · Characterization · Volatile compounds · Geographical origin · Computational statistics

\section{Introduction}

Ioannis K. Karabagias

ikaraba@uoi.gr

$\triangle$ Nikolaos Kopsahelis

kopsahelis@upatras.gr; kopsahelis@ionio.gr

1 Department of Food Science and Technology, Ionian University, 28100 Argostoli, Kefalonia, Greece

2 Laboratory of Food Chemistry, Department of Chemistry, University of Ioannina, 45110 Ioannina, Greece

3 Department of Food Science and Technology, School of Agricultural Sciences, University of Patras, Charilaou Trikoupi 2, 30100 Agrinio, Greece

4 Department of Food Science and Human Nutrition, Agricultural University of Athens, Iera Odos 75, 11855 Athens, Greece

5 Department of Environment, Ionian University, M. Minotou-Giannopoulou, 29100 Zakynthos, Greece
Olive oil comprises a long-term ingredient in the Mediterranean cuisine and diet, including ancient Greek and Roman cuisine [1]. Olive oil is a liquid source of fat obtained from olives (Olea europaea) and is produced by pressing the olives and extracting the respective oil. It is mainly consisted by oleic acid with smaller amounts of other fatty acids including linoleic acid and palmitic acid, phenols, tocopherols, sterols, phospholipids, waxes, squalene and other hydrocarbons [2].

According to the United States Department of Agriculture, the global olive oil production in the 2020/2021 harvesting season was ca. 3.03 million tons, which represents the fourth successive year of decline in terms of quantity [3]. Among the olive oil producing countries, Morocco, Tunisia, Turkey and Portugal had all a decrease in the production yield, whilst the olive oil production in Greece and Spain remained fairly stable. Spain accounts for almost half of the global olive oil production; other major olive oil producers are Italy, Greece, Tunisia, and Turkey [4]. 
To ensure and keep flourishing the production/distribution of olive oil and other foodstuffs the agro-food sector must develop new strategies/innovations due to the challenges of our time. A typical example comprises the COVID 19 pandemic crisis during which the food companies are forced to seek new information and knowledge about consumer needs toward natural products with beneficial health effects, such as functional foods [5]. The functional foods and other nutraceuticals contain bioactive compounds such as vitamins, bioactive lipids, flavonoids, bioactive peptides, polysaccharides, bioactive lipids, and natural polyphenols [6], while highlight the advances of a potential nutrition to strengthen consumers' immune system and improve their overall health [7]. Nowadays, the production of these types of products is enhanced in parallel with the valorization of bio-resources; i.e., the recoveries of high added-value compounds from food waste [5]. A typical food waste may also comprise the olive oil waste and future exploitation may lead to beneficial effects for human health, as a shield against COVID 19 and related pandemic diseases. An authentic raw material with unique composition may also give a beneficial by-product.

The composition of olive oil varies according to the cultivar, altitude, harvesting year and extraction processing techniques. The unique characteristics of each cultivar in relation to the climatic conditions, agronomic practices, geographical production area, harvesting practices, and processing technology are closely related to the olive oil quality and composition $[2,8]$. The quality characteristics of a genuine olive oil may allow its labeling as PDO (Protected Designation of Origin) or PGI (Protected Geographical Indication) as supported and encouraged by the European Commission [9]. Thus, authenticity of olive oil is an important topic for stakeholders. The term authentication covers plenty aspects, such as characterization, geographical origin determination, cultivar differentiation, and adulteration [10-14]. The determination of olive oil uniqueness is accomplished after implementation of different techniques that provide numerical data regarding its quality indices, sensory characteristics and composition during production and storage [15-23].

Some typical instrumental techniques that have been widely used for the characterization of olive oil composition and its authentication are headspace solid phase microextraction coupled to gas chromatography/mass spectrometry $[12,24-28]$, gas chromatography coupled to flame ionization detector [29, 30], stable isotope ratio analysis (SIRA) in combination with mineral content analysis [31], nuclear magnetic resonance (NMR) [1, 32], specific natural isotopic fractionation nuclear magnetic resonance (SNIF/NMR) [33], high performance liquid chromatography (HPLC) alone or in combination with mass spectrometry [34], DNA-encoding techniques [35] and the newly developed paper-based optoelectronic nose [36], in combination with computational statistics such as multivariate analysis of variance, principal component analysis, linear discriminant analysis, partial-least squares discriminant analysis, etc. [1, 12, 26, 27, $29,30]$. New trends in food analysis include the separation of functional macro-molecules and micro-molecules using ultrafiltration and nanofiltration techniques [37].

As far as the volatile profile of olive oil, it is highly correlated with its organoleptic properties, as volatile compounds are responsible for both positive and negative olfactory characteristics $[38,39]$ contributing further to its qualitative characteristics [17, 18]. A previous study reported data for olive oil samples of the "Ntopia" cultivar from Zakynthos, Leukada, and Kerkyra concerning the quality indices and physicochemical composition on the basis of acidity (0.25-1.27\% of oleic acid), peroxide value (6.87-72.49 $\left.\mathrm{meqO}_{2} / \mathrm{kg}\right), \mathrm{K}_{232}(1.31-15.95), \mathrm{K}_{270}(0.10-1.74), \Delta \mathrm{K}$ ( -0.004 to 1.03$)$ extraction coefficients, chlorophyll and carotenoid contents $(0.08-4.46 \mathrm{mg} / \mathrm{kg}$ of pheophytin A and $0.87-2.22 \mathrm{mg} / \mathrm{kg}$ of lutein, respectively) and fatty acid content (myristic acid $0.01-0.02 \%$; margaric acid $0.01-0.10 \%$; stearic acid 1.83-3.35\%; arachidic acid $0.35-0.46 \%$; and eicosenoic acid $0.21-0.31 \%$ ) [30].

Taking into account the aforementioned, the aim of the present study was to characterize the aroma profile of olive oil of the "Ntopia" (local) cultivar and investigate if specific volatile compounds could aid in the geographical origin discrimination of this type of olive oil harvested in Ionian islands, in combination with computational statistics. In confidence, there is not a previous study in the literature reporting volatile compounds analysis data for olive oil of the "Ntopia" cultivar and their potential use in the authentication control of this type of olive oil, thus constituting the originality of the present study.

\section{Materials and methods}

\section{Olive oil samples}

One hundred and thirty-seven virgin olive oil (VOO) samples $(N=137)$ were obtained using olives from four different Ionian islands in Greece: Zakynthos ( $37^{\circ} 48^{\prime} \mathrm{N} 20^{\circ} 45^{\prime} \mathrm{E}$ ) ( $N=33$ samples), Kefalonia ( $38^{\circ} 15^{\prime} 54^{\prime \prime}$ N $\left.20^{\circ} 33^{\prime} 09^{\prime \prime} \mathrm{E}\right)$ $(N=31$ samples $)$, Leukada $\left(38^{\circ} 43^{\prime} \mathrm{N} 20^{\circ} 39^{\prime} \mathrm{E}\right)(N=36$ samples), and Kerkyra (39 $\left.35^{\circ} 28.60^{\prime \prime} \mathrm{N} 19^{\circ} 51^{\prime} 50.54^{\prime \prime} \mathrm{E}\right)$ ( $N=37$ samples). Following the Köppen-Geiger climate classification system, all four islands are classified as "Csa" (hot dry-summer climates), which constitutes a sub-class of Mediterranean climate, characterized by temperate, dry hot summer, also known as thermo-Mediterranean zone. Likewise, the average annual temperatures and precipitation are $18.2,18.5,15.4,17.1^{\circ} \mathrm{C}$ and 995, 804, 1194, $1290 \mathrm{~mm}$ for Zakynthos, Kefalonia, Leukada and Kerkyra islands, 
respectively. The average temperature during the harvesting month was $16.9,15.9,17.1$ and $15.3{ }^{\circ} \mathrm{C}$, whereas the altitude of sample collection was 20-460, 20-400, 50-700 and 20-500 m for Zakynthos, Kefalonia, Leukada and Kerkyra, respectively. Supplementary Tables $1-4$ give information on the harvesting year and the regions of collection of samples which cover the wider areas of the Ionian islands. In particular, the majority of olive trees grown in Zakynthos and Kefalonia belong to the domestic cultivar "Ntopia", whereas those of Leukada belong to "Asprolia" cultivar and those of Kerkyra to "Lianolia" cultivar. However, both "Asprolia" and "Lianolia" cultivars are the major "local" domestic cultivars of these islands, contributing thus, to the general group of "Ntopia" cultivars from Ionian islands. During the collection of samples of olives, the following factors were taken into account:

(i) The fruits had the same degree of maturity. For this reason, the time of harvesting of the olive fruit was defined as the time when the fruit begun to change color, and

(ii) Collection of samples covering as much as possible all the olive growing areas of the Islands.

Immediately, after receiving the raw material (approximately $3 \mathrm{~kg} / \mathrm{sample}$ ), the following procedure was followed: 1. Selection of olives and leaves: only healthy olives and without any imperfections were used; 2 . Crushing of olives and removal of olive core; 3 . Grinding in blender; 4 . Adding an equal amount of water and mixing the olive oil for $45 \mathrm{~min}$ at a temperature below $27^{\circ} \mathrm{C} ; 5$. Centrifuging for $4 \mathrm{~min}$ at 3500 revolutions per minute (rpm); and 6 . Receiving of olive oil, archiving and placing samples in dark vials under chilled temperature.

\section{Chemicals and reagents}

4-methyl-2-pentanone $\left[\left(\mathrm{CH}_{3}\right)_{2} \mathrm{CHCH}_{2} \mathrm{COCH}_{3}\right.$, $\mathrm{MW}=100.16]$ used as internal standard was purchased from Fluka (Germany). The standard mixture of alkanes $\mathrm{C}_{8}-\mathrm{C}_{20}$ (40 $\mathrm{mg} / \mathrm{L}$ each in $n$-hexane) was purchased from SigmaAldrich (Germany).

\section{Determination of olive oil volatile compounds}

\section{Fiber cleaning}

The extraction of volatile compounds dominating the headspace of olive oil samples was done using a divinyl benzene/carboxen/polydimethylsiloxane (DVB/CAR/PDMS) fiber of $50 / 30 \mu \mathrm{m}$ purchased by Supelco (Bellefonte, PA, USA). Before the analysis of samples the fiber was cleaned daily using the method of the "clean" program. During the "cleaning" of the fiber, oven temperature was held at $80^{\circ} \mathrm{C}$ for $0 \mathrm{~min}$, and then increased to $260{ }^{\circ} \mathrm{C}$ at a rate of $10{ }^{\circ} \mathrm{C} /$ $\min (2$ min hold $)$. The inlet temperature was $270{ }^{\circ} \mathrm{C}$. The auxiliary temperature was $280^{\circ} \mathrm{C}$ and that of the MS source $230{ }^{\circ} \mathrm{C}$.

\section{Preparation of olive oil samples for headspace solid phase microextraction (HS-SPME)}

Approximately, $4 \mathrm{~g}$ of olive oil was placed in $20 \mathrm{~mL}$ screwcap vials equipped with polytetrafluoroethylene (PTFE)/ silicone septa and $100 \mu \mathrm{L}$ of the internal standard (4-methyl2-pentanone of initial concentration of $500 \mu \mathrm{g} / \mathrm{L}$ ) was added. 4-methyl-2-pentanone was chosen as an internal standard during the optimization of the method given that it did not occur in any of the olive oil volatiles compounds and did not cause any co-elution problems. The vials were vortexed and maintained in a water bath at $45^{\circ} \mathrm{C}$ under stirring at $600 \mathrm{rpm}$ during the extraction procedure with the fiber. The HSSPME extraction procedure included the optimized conditions: 15 min equilibration time, $15 \mathrm{~min}$ sampling/exposure time of the fiber, weight of sample $4 \mathrm{~g}$, vial volume $20 \mathrm{~mL}$, and as reported above, constant extraction temperature of the water bath at $45{ }^{\circ} \mathrm{C}$ (Supplementary Table 5).

\section{Instrumentation and analytical conditions}

A gas chromatograph (GC) unit (Agilent 7890 A) coupled to a mass spectrometry (MS) detector (Agilent 5975) was used for the analysis of olive oil volatile compounds. A DB-5MS [cross-linked (5\%-Phenyl)-methylpolysiloxane)] capillary column (J \& W Scientific, Agilent Technologies, Santa Clara, CA, USA), with dimensions of $60 \mathrm{~m} \times 320 \mu \mathrm{m}$ i.d., $\times 1 \mu \mathrm{m}$ film thickness was used, with helium as the carrier gas (purity $99.999 \%$ ), at a flow rate of $1.5 \mathrm{~mL} / \mathrm{min}$. The temperature for the injector and MS-transfer line were maintained constant at $260{ }^{\circ} \mathrm{C}$ and $270{ }^{\circ} \mathrm{C}$, respectively. The oven temperature was held at $40{ }^{\circ} \mathrm{C}$ for 4 min and was further increased to $160{ }^{\circ} \mathrm{C}$ at a rate of $4{ }^{\circ} \mathrm{C} / \mathrm{min}$ for $2 \mathrm{~min}$, increasing further to $250{ }^{\circ} \mathrm{C}$ at a rate of $8{ }^{\circ} \mathrm{C} / \mathrm{min}$ for $2 \mathrm{~min}$. Electron impact mass spectra were recorded at the mass range of 29-500. The ionization energy of the electron ionization system was $70 \mathrm{eV}$. A split ratio 2:1 was used.

\section{Identification of olive oil volatile compounds}

The identification of olive oil volatile compounds was done based on the Wiley 7 NIST (National Institute of Standards and Technology) mass spectral library (NIST 2005) (J. Wiley \& Sons Ltd., West Sussex, England). For the determination of the linear retention index values, the mixture of $n$-alkanes $\left(\mathrm{C}_{8}-\mathrm{C}_{20}\right)$ was used (Supplementary Table 6). The calculation of retention time indices was carried out for 
volatile compounds eluting between $n$-octane and $n$-eicosane according to Kováts formula:

$I_{i}=100 \times\left[n+\left(t_{i}-t_{n}\right) /\left(t_{n+1}-t_{n}\right)\right]$,

where $t_{n}$ and $t_{n+1}$ are the retention times of heading and trailing $n$-alkanes and $t_{i}$ is the retention time of the volatile compound of interest [40].

\section{Expression of results}

Results were expressed as semi-quantitative data according to the formula:

Volatile compounds $(\mu \mathrm{g} / \mathrm{L})=\left(E_{\text {analyte }} / E_{\mathrm{IS}}\right) \times C_{\mathrm{IS}}$,

where $E_{\text {analyte }}$ refers to the peak area of analyte, $E_{\mathrm{IS}}$ refers to the peak area of internal standard (IS), and $C_{\mathrm{IS}}$ : final concentration of IS.

To eliminate any kind of contamination that could cause memory effects, affecting thus, the obtained results, blank runs were carried out before and after the analysis of olive oil samples.

\section{Computational statistics}

The semi-quantitative data $(\mu \mathrm{g} / \mathrm{L})$ of volatile compounds were subjected to chemometric analysis to investigate the impact of geographical origin on the volatile composition of olive oil samples. Comparison of the average values was done using multivariate analysis of variance (MANOVA) to determine which volatile compounds showed significant differences $(p<0.05)$ in their composition among olive oil samples of different geographical origin (Zakynthos, Kefalonia, Leukada, and Kerkyra islands). MANOVA creates a new dependent variable based on the linear combination of all the dependent variables in the model, which maximizes as far as possible the differences in the average values between the level groups of the independent variable. Various criteria in the multi-parametric hypothesis are used to study the main effects and interaction of the independent variables at the multi-parametric level. The Wilks' Lambda criterion is the most widely used indicator, i.e., the one used in the majority of studies/surveys. From the Wilks' Lambda index, we can have a quick estimate of the effectiveness of the conducted research. Therefore, the smaller the Wilks' Lambda index, the greater the differences between the studied groups. Another index used in the multi-parametric hypothesis is the Pillai's Trace. This indicator corresponds essentially to the dispersion between the combinations of the studied groups. It is mentioned in the literature as the most stable multi-parametric indicator if the compared groups have different number of population, and is essentially suggested for this reason [41].
Factor analysis describes the variability (variance) that exists between a number of measured (obvious) and associated variables, on the basis of a smaller number of non-obvious variables, called factors. The purpose of factor analysis is to summarize the relationships between a large number of variables in a comprehensive and accurate way to help make a concept or property more perceptible, while providing percentages of variance (\% variance). In the factorial analysis, the Kaiser-Meyer-Olkin index (KMO) assesses the sample adequacy (it should be $>0.50$ ), while Bartlett's Test of Sphericity ( $p$ value should be $<0.05$ ) assesses whether the correlations between the variables allow the implementation of factor analysis [42]. The extraction method was principal component analysis (PCA). PCA is defined as an orthogonal linear transformation that transforms the data to a new coordinate system such that the greatest variance by some scalar projection of the data comes to lie on the first coordinate (called the first principal component), the second greatest variance on the second coordinate, and so on [43]. The rotation method used was Varimax with Kaiser Normalization. Varimax rotation is used in statistical analysis to simplify the expression of a particular sub-space in terms of just a few major items dominating the poly-parametric space. The actual coordinate system (practically unchanged) is the orthogonal basis that is being rotated to align with these coordinates. The sub-space can be defined with either PCA or FA. Varimax maximizes the sum of the variances of the squared loadings (squared correlations between factor variables) [42].

Linear discriminant analysis (LDA) is a supervised statistical technique that aims to find a linear combination of the statistically significant volatile compounds (indicated during MANOVA) that separate two or more groups of objects (i.e., geographical origin). The goodness of the prediction ability of the LDA models was evaluated by the cross-validation method [44]. For the LDA analysis, the geographical origin of olive oil samples was considered as the factor variable (group variable), while the semi-quantitative data of the volatile compounds as the independent variables. Validation of the LDA results was carried out using training and holdout partitions (K-nearest neighbor analysis, KNN). Computational statistics were accomplished using the Statistical Package for the Social Sciences (SPSS) version 26.0 statistics software (SPSS, IBM Inc., 2019).

\section{Results and discussion}

\section{Volatile compounds of olive oil from different geographical origin}

Table 1 shows the semi-quantitative data of the volatile compounds that were identified among olive oil samples of the 
Table 1 Volatile compounds identified in olive oil of the "Ntopia" cultivar from Ionian islands and corresponding aroma notes

\begin{tabular}{|c|c|c|c|c|c|c|c|}
\hline $\begin{array}{l}\text { Retention time } \\
(\mathrm{RT}, \mathrm{min})\end{array}$ & $\begin{array}{l}\text { Volatile compounds } \\
(\mu \mathrm{g} / \mathrm{L})\end{array}$ & $\mathrm{RI}^{\mathrm{a}}$ & $\begin{array}{l}\text { Zakynthos } \\
(\text { Avg } \pm \text { SD) }\end{array}$ & $\begin{array}{l}\text { Kefalonia } \\
(\text { Avg } \pm \text { SD })\end{array}$ & $\begin{array}{l}\text { Leukada } \\
(\text { Avg } \pm \mathrm{SD})\end{array}$ & $\begin{array}{l}\text { Kerkyra } \\
(\text { Avg } \pm S D)\end{array}$ & Aroma/Reference \\
\hline & Alcohols & & & & & & \\
\hline 5.70 & Ethanol & $<800$ & $8.56 \pm 10.61$ & $5.82 \pm 4.39$ & $5.05 \pm 4.25$ & $3.33 \pm 4.62$ & $\begin{array}{l}\text { Fermented-like, ripe fruit, } \\
\text { pungent [2] }\end{array}$ \\
\hline 8.10 & 1-propanol & $<800$ & $\mathrm{Nd}$ & $\mathrm{Nd}$ & $0.23 \pm 0.37$ & $\mathrm{Nd}$ & Fermented-like \\
\hline 22.25 & 2-hexen-1-ol, (E)- & 927 & $3.61 \pm 3.72$ & $2.51 \pm 2.89$ & $1.96 \pm 2.74$ & $4.96 \pm 4.75$ & $\begin{array}{l}\text { Fruity, fatty, pungent, cut grass } \\
\quad[25,52]\end{array}$ \\
\hline \multirow[t]{3}{*}{22.38} & 1-hexanol & 930 & $4.05 \pm 4.55$ & $\mathrm{Nd}$ & $\mathrm{Nd}$ & $\mathrm{Nd}$ & $\begin{array}{l}\text { Fruity, aromatic, soft, cut grass } \\
\text { [25] }\end{array}$ \\
\hline & Sum of alcohols & & 16.22 & 8.33 & 7.24 & 8.29 & \\
\hline & Aldehydes & & & & & & \\
\hline 14.00 & Pentanal & $<800$ & $\mathrm{Nd}$ & $1.73 \pm 1.18$ & $1.78 \pm 1.76$ & $\mathrm{Nd}$ & Pleasant [2] \\
\hline 19.15 & Hexanal & 862 & $7.18 \pm 3.59$ & $4.96 \pm 2.93$ & $5.40 \pm 2.35$ & $6.99 \pm 2.09$ & Green, apple, cut grass $[25,53]$ \\
\hline 21,86 & 2-hexenal, (E)- & 919 & $25.63 \pm 18.22$ & $35.65 \pm 21.89$ & $24.50 \pm 10.41$ & $46.78 \pm 24.16$ & $\begin{array}{l}\text { Bitter, almonds, green, green } \\
\text { apple-like, fatty, bitter } \\
\text { almond-like, cut grass [25, } \\
52]\end{array}$ \\
\hline 24.16 & Heptanal & 968 & $1.37 \pm 2.16$ & $\mathrm{Nd}$ & $\mathrm{Nd}$ & $\mathrm{Nd}$ & Strong fruity [49] \\
\hline 28.90 & Octanal & 1078 & $1.76 \pm 2.65$ & $\mathrm{Nd}$ & $\mathrm{Nd}$ & $\mathrm{Nd}$ & Fruity [49] \\
\hline \multirow[t]{3}{*}{33.30} & Nonanal & 1184 & $9.61 \pm 6.79$ & $3.70 \pm 4.85$ & $2.98 \pm 3.07$ & $6.03 \pm 4.34$ & $\begin{array}{l}\text { Soapy (undesirable), citrus-like } \\
{[25,53]}\end{array}$ \\
\hline & Sum of aldehydes & & 45.55 & 46.04 & 34.66 & 59.80 & \\
\hline & Benzene derivatives & & & & & & \\
\hline 17.71 & Toluene & 831 & $\mathrm{Nd}$ & $\mathrm{Nd}$ & $\mathrm{Nd}$ & $4.85 \pm 12.44$ & Bitter, spicy oil [2] \\
\hline \multirow[t]{3}{*}{39.47} & $\begin{array}{l}\text { Benzene, 1,3-bis(1,1-dimeth- } \\
\text { ylethyl)- }\end{array}$ & 1348 & $5.80 \pm 2.81$ & $4.05 \pm 1.59$ & $3.57 \pm 1.41$ & $3.38 \pm 1.57$ & Bitter, spicy oil [2] \\
\hline & Sum of benzene derivatives & & 5.80 & 4.05 & 3.57 & 8.23 & \\
\hline & Esters and derivatives & & & & & & \\
\hline 28.82 & 3-hexen-1-ol, acetate, (Z) & 1076 & $\mathrm{Nd}$ & $10.14 \pm 10.55$ & $4.08 \pm 3.23$ & $\mathrm{Nd}$ & $\begin{array}{l}\text { Fruity, sweet, pleasant aromatic } \\
\text { notes }[2,26]\end{array}$ \\
\hline \multirow[t]{3}{*}{29.06} & Acetic acid, hexyl ester & 1081 & $\mathrm{Nd}$ & $\mathrm{Nd}$ & $1.76 \pm 2.15$ & $\mathrm{Nd}$ & $\begin{array}{l}\text { Fruity, sweet, pleasant aromatic } \\
\text { notes }[2,26]\end{array}$ \\
\hline & Sum of esters and derivatives & & $\mathrm{Nd}$ & 10.14 & 5.84 & $\mathrm{Nd}$ & \\
\hline & Hydrocarbons & & & & & & \\
\hline 7.28 & 1,3-pentadiene, $(\mathrm{Z})$ - & $<800$ & $\mathrm{Nd}$ & $\mathrm{Nd}$ & $0.23 \pm 0.37$ & $\mathrm{Nd}$ & Aromatic, sweet, apple [2] \\
\hline 20.15 & Heptane, 2,4-dimethyl- & 862 & $\mathrm{Nd}$ & $1.38 \pm 1.06$ & $0.82 \pm 1.04$ & $1.61 \pm 0.87$ & Aromatic, sweet, apple [2] \\
\hline 28.49 & $\begin{array}{l}\text { Heptane, 2,2,4,6,6-penta- } \\
\text { methyl- }\end{array}$ & 1068 & $6.03 \pm 2.45$ & $5.73 \pm 3.02$ & $5.22 \pm 2.18$ & $3.91 \pm 2.31$ & Aromatic, sweet, apple [2] \\
\hline 28.67 & Decane & 1072 & $5.62 \pm 2.60$ & $4.98 \pm 1.88$ & $1.95 \pm 1.59$ & $6.10 \pm 1.29$ & Aromatic, sweet, apple [2] \\
\hline 29.46 & Nonane, 2,5-dimethyl- & 1091 & $0.59 \pm 065$ & $\mathrm{Nd}$ & $\mathrm{Nd}$ & $\mathrm{Nd}$ & Aromatic, sweet, apple [2] \\
\hline 29.65 & Decane, 4-methyl- & 1095 & $\mathrm{Nd}$ & $\mathrm{Nd}$ & $1.07 \pm 1.16$ & $1.31 \pm 1.19$ & Aromatic, sweet, apple [2] \\
\hline \multirow[t]{3}{*}{37.30} & Dodecane & 1283 & $4.57 \pm 2.41$ & $2.80 \pm 1.65$ & $2.22 \pm 1.62$ & $3.67 \pm 1.83$ & Aromatic, sweet, apple [2] \\
\hline & Sum of hydrocarbons & & 16.81 & 14.89 & 11.51 & 16.60 & \\
\hline & Ketones & & & & & & \\
\hline \multirow[t]{3}{*}{28.01} & 5-hepten-2-one, 6-methyl & 1056 & $7.43 \pm 6.12$ & $2.82 \pm 3.86$ & $\mathrm{Nd}$ & $2.27 \pm 1.90$ & Pungent, green, fruity [48] \\
\hline & Sum of ketones & & 7.43 & 2.82 & $\mathrm{Nd}$ & 2.27 & \\
\hline & Terpenoids & & & & & & \\
\hline 30.46 & $\begin{array}{l}\text { 1-methyl-4-(prop-1-en-2-yl) } \\
\text { cyclohex-1-ene (dl- } \\
\text { Limonene) }\end{array}$ & 1115 & $\mathrm{Nd}$ & $\mathrm{Nd}$ & $\mathrm{Nd}$ & $0.58 \pm 0.71$ & Pleasant [49] \\
\hline \multirow[t]{2}{*}{30.79} & $\begin{array}{l}\text { 1,3,6-octatriene, 3,7-dime- } \\
\text { thyl-, (E)-(trans- } \beta \text { - } \\
\text { Ocimene) }\end{array}$ & 1123 & $4.89 \pm 4.87$ & $\mathrm{Nd}$ & $\mathrm{Nd}$ & $2.29 \pm 1.72$ & Pleasant [49] \\
\hline & Sum of terpenoids & & 4.89 & $\mathrm{Nd}$ & $\mathrm{Nd}$ & 2.87 & \\
\hline
\end{tabular}

$N d$ not determined, $A v g \pm S D$ average \pm standard deviation

${ }^{a}$ Experimental retention time indices according to Kováts equation 
"Ntopia" cultivar of different geographical origin and the respective aroma notes these possess. In total, 24 volatile compounds were identified belonging to aldehydes, alcohols, esters and their derivatives, hydrocarbons, ketones, terpenoids, and phenolic derivatives. Among these compounds, ethanol, hexanal, (E)-2-hexenal, (E)-2-hexen-1-ol, 2,2,4,6,6-pentamethylheptane, decane, nonanal, dodecane, and 1,3-bis(1,1-dimethylethyl)benzene were identified in all the 137 olive oil samples. A typical gas chromatogram of olive oil sample (no.99) from Kefalonia is shown in Fig. 1. The volatile compounds that were identified in the present study are in accordance with previous studies dealing with the cultivar or geographical origin determination of olive oil either from Greece [12, 26, 28, 29] or other countries [16-18, 20, 22, 27, 34, 38, 39].

Differences in the volatile composition of olive oil samples of different geographical origin were observed. In addition, substantial differences were observed in the sum of volatile compounds classes according to geographical origin of olive oil. The most dominant volatile compounds were aldehydes, followed by hydrocarbons, and alcohols. The total volatile composition of classes of volatile compounds (which is derived by the sum of the individual composition of classes of volatiles in each geographical origin) followed the order: Aldehydes $(186.05 \mu \mathrm{g} / \mathrm{L})>$ Hydrocarbons $(59.81 \mu \mathrm{g} / \mathrm{L})>$ Alcohols $(40.08 \mu \mathrm{g} / \mathrm{L})>$ Benzene derivatives $(21.65 \mu \mathrm{g} / \mathrm{L})>$ Esters and derivatives $(15.98 \mu \mathrm{g} / \mathrm{L})>$ Ketones $(12.52 \mu \mathrm{g} / \mathrm{L})>$ Terpenoids $(7.76 \mu \mathrm{g} / \mathrm{L})$ (Table 1$)$.
During the production process of olive oil and its chemical oxidation, most of the volatile compounds with 5 and 6 carbon atoms (C5 and C6), which in turn are responsible for the typical fruity and green notes of olive oil, are produced by the lipoxygenase (LOX) enzyme pathway [14, 21, 24, 27, $38,45]$. The LOX pathway involves enzymes that oxidize (lipoxygenase) and cleave (hydroperoxide lyase) polyunsaturated fatty acids to aldehydes. These in turn, are reduced to alcohols (by alcohol dehydrogenase) and esterified to produce esters (by alcohol acyltransferase).

The main volatiles that contribute to olive oil aroma are hexanal, the aroma of which is associated with green apple and cut grass; trans-2-hexenal, [E] or (E)-2-hexenal, the aroma of which is associated with that of bitter almonds, and other green, fruity, sharp, bitter and astringent aromas; and the 1-hexanol, the aroma of which is related to that of tomato and other fruity, soft, aromatic, alcoholic and harsh aromas [28, 46, 47].

Among aldehydes, hexanal recorded the higher concentration in olive oil samples from Zakynthos, whereas (E)2-hexenal, the most abundant in concentration, recorded the higher value in olive oil samples from Kerkyra. Of the other respective aldehydes, nonanal recorded the higher concentration in olive oil samples from Zakynthos, while heptanal and octanal were identified only in olive oil samples from Zakynthos. Present results are in agreement with those of Theodosi et al. [28] who studied the volatile profile of olive oil samples of the Koroneiki cultivar from Zakynthos.

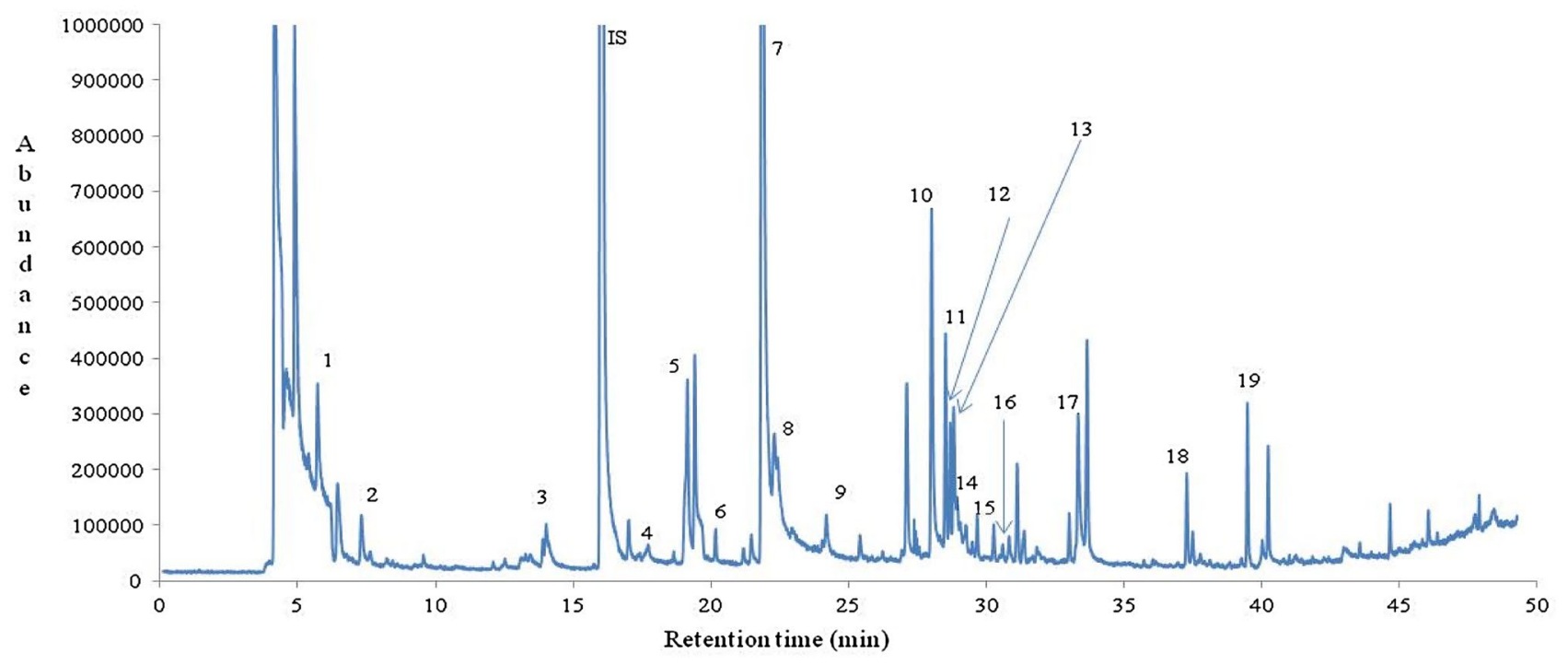

Fig. 1 A typical gas chromatogram of olive oil (sample no. 99) of the "Ntopia" cultivar from Kefalonia island pointing out with numbers some key volatile compounds serving as indicators of the geographical origin of olive oil from Ionian islands. 1: Ethanol; 2: 1,3-Pentadiene, (Z); 3: Pentanal; 4: Toluene; 5: Hexanal; 6: Heptane, 2,4-dimethyl-; 7: 2-Hexenal, (E)-; 8: 2-Hexen-1-ol, (E)-; 9: Heptanal; 10:
5-Hepten-2-one, 6-methyl-; 11: Heptane, 2,2,4,6,6-pentamethyl-; 12: Decane; 13: 3-Hexen-1-ol, acetate, (Z)-; 14: Nonane, 2,5-dimethyl-; 15: Decane, 4-methyl-; 16: 1,3,6-Octatriene, 3,7-dimethyl-, (E)-; 17: Nonanal; 18: Dodecane; 19: Benzene, 1,3-bis(1,1-dimethylethyl)-; IS internal standard 
Pentanal recorded the higher concentration in olive oil samples from Leukada (Table 1).

Concerning the alcohols, ethanol was identified in all olive oil samples and recorded the higher concentration in olive oil samples from Zakynthos. Ethanol may give a fermented-like, ripe fruit, and pungent aroma in olive oil, while in combination with other alcohols such as 2-methylpropanol, pentanal, cis-2-penten-1-ol, cis-3-hexenol and octanol may give a sweet and fruity odor, resulting in positive effects to the aroma and quality of olive oil [2]. Previous studies in the literature dealing with the determination of volatile compounds of olive oil from Morocco (Picholine marocaine cultivar) [13], Brazil (Arbequina, Arbosana, Picual, Koroneiki, Grapollo, Coratina and Frantoio cultivars) [20], Greece (Koroneiki cultivar) [28], and Italy (Leccino cultivar) [22] did not report the presence of ethanol in the aroma of olive oil samples. However, in the Italian olive cultivar "Alperujo" ethanol was identified in olive oil during the analysis of volatile compounds [39]. Therefore, ethanol may be proposed as a characteristic volatile compound of olive oil associated with its cultivar, giving thus, some special sensory characteristics to olive oil.

1-Hexanol was identified only in olive oil samples from Zakynthos, whereas (E)-2-hexen-1-ol recorded the higher concentration in olive oil samples from Kerkyra (Table 1). This compound has been associated with a "green "and "grassy" odor [2] and astringent-bitter taste of olive oil [26]. Finally, 1-propanol was identified only in olive oil samples from Leukada, in small amounts (Table 1). 1-Propanol was reported previously to contribute to the aroma of olive oil of the Leccino cultivar from Italy [22].

Hydrocarbons may also be derived from the LOX pathway [14]. The most abundant hydrocarbons were 2,2,4,6,6-pentamethylheptane and decane. Decane recorded the higher concentration in olive oil samples from Kerkyra, whereas 2,2,4,6,6-pentamethylheptane recorded the higher concentration in olive oil samples from Zakynthos. It is worth mentioning, the contribution of dodecane in the aroma of olive oil samples of the "Ntopia" cultivar, which recorded the highest concentration in olive oil samples from Zakynthos (Table 1). Another critical point to discuss is that these hydrocarbons were not reported to contribute to the aroma of olive oil of the Koroneiki cultivar from Zakynthos [28], considered thus, as characteristic volatiles of olive oil of the "Ntopia" cultivar from Zakynthos. Depending on the carbon chain, hydrocarbons may give an aromatic, sweet, apple-like, and oily odor in olive oil [2].

Among ketones, only 6-methyl-5-hepten-2-one was identified in olive oil samples from Zakynthos, Kefalonia, and Kerkyra. It was determined in higher concentrations in olive oil samples from Zakynthos, in agreement with the results reported by Theodosi et al. [28]. This compound contributes to the pungent, green, and fruity odor of olive oil [48].
Acetic acid hexyl ester and 3-hexen-1-ol, acetate, (Z), were the only esterified products that were identified in olive oil samples. Acetic acid hexyl ester was identified only in olive oil samples from Leukada, whereas 3-hexen-1-ol, acetate, $(Z)$ recorded the higher concentration in olive oil samples from Kefalonia. Acetic acid hexyl ester had different concentration in olive oil samples of the Koroneiki cultivar from Zakynthos [28]. These compounds also derive from the LOX pathway and contribute to the fruity, sweet and pleasant aromatic notes of olive oil [2, 26].

Regarding benzene derivatives, toluene was identified only in olive oil samples from Kerkyra. On the contrary, 1,3-bis(1,1-dimethylethyl)benzene was identified in all olive oil samples, recording higher concentration in samples from Zakynthos. This benzene derivative was not reported previously to contribute to the aroma of olive oil of the Koroneiki cultivar from Zakynthos [28], Picholine marocaine cultivar from Morocco [13], and Alperujo cultivar from Florence (Italy) [39], whereas scarce data are available, in general, for this compound in the relevant literature [2, 13, 22, 23, $28,39]$. These phenolic volatiles may give olive oil a bitter and spicy oil flavor [2].

Finally, terpenoids such as dl-limonene and trans- $\beta$ ocimene may vary in their respective concentration according to cultivar and geographical origin $[28,48]$. In the present study, dl-limonene was identified only in olive oil samples from Kerkyra, whereas trans- $\beta$-ocimene had the higher concentration in olive oil samples from Zakynthos, in agreement with the results reported by Theodosi et al. [28]. These volatile compounds may give olive oil a pleasant odor [49].

The importance of the aroma characterization of olive oil is mandatory for its quality level, given that the compounds that contribute to the aroma are volatile compounds that are perceived by the olfactory receptors of the nasal cavity. The complexity of food flavor is owed to a mixture of volatile and non-volatile molecules in relation to the moisture content of foodstuffs. These substances reach the receptors either through the nose during inhalation or through the throat and after being released during the chewing process [50] and create the basis for rejection or acceptance of the product. Actually, it is known that a specific compound can contribute positively to the aroma and/or taste (flavor) of one food, while in another it can cause an unpleasant aroma or taste or both [21].

\section{Geographical origin discrimination of "Ntopia" olive oil cultivar from Zakynthos and Kefalonia islands}

\section{MANOVA}

The qualitative criteria of the multivariate hypothesis, namely Pillai's Trace $=0.895(F=19.765, \mathrm{~d} f=19$, 
$p=0.000)$, and Wilks' Lambda $=0.105(F=19.765, \mathrm{~d} f=19$, $p=0.000$ ) showed that there was a significant impact of geographical origin on the volatile composition of olive oil samples from the "Ntopia" cultivar. In Supplementary Table 7, one can observe the function values (F-distribution), degrees of freedom and the level of confidence of the volatile compounds in relation to the geographical origin (Zakynthos and Kefalonia). Each $F$ value tests the multivariate effect of the geographical origin of olive oil on volatile compounds composition. Fourteen volatile compounds showed significant differences $(p<0.05)$ in their composition according to the geographical origin of olive oil. These volatile compounds are given in Supplementary Table 6 and the factor analysis section that follows.

\section{FA}

Factor analysis showed that the 14 statistically significant volatile compounds adequately describe the variability in the poly-parametric space. The Kaiser-Meyer-Olkin (KMO) index was 0.640, while Bartlett's Test of Sphericity index had the values $X^{2}=500.505, \mathrm{~d} f=91, p=0.000$, indicating that there are correlations between the variables that allow the application of factor analysis. The main volatile compounds that showed the highest correlation (factors) are given in bold in Table 2 .

Based on the first four principal components (PCs) the variance explained was $69.812 \%$, considered as satisfactory (Fig. 2). The volatile compounds for which the correlation value in the rotated component matrix of the poly-parametric space was the largest were: Octanal (PC1,

\section{Component Plot in Rotated Space}

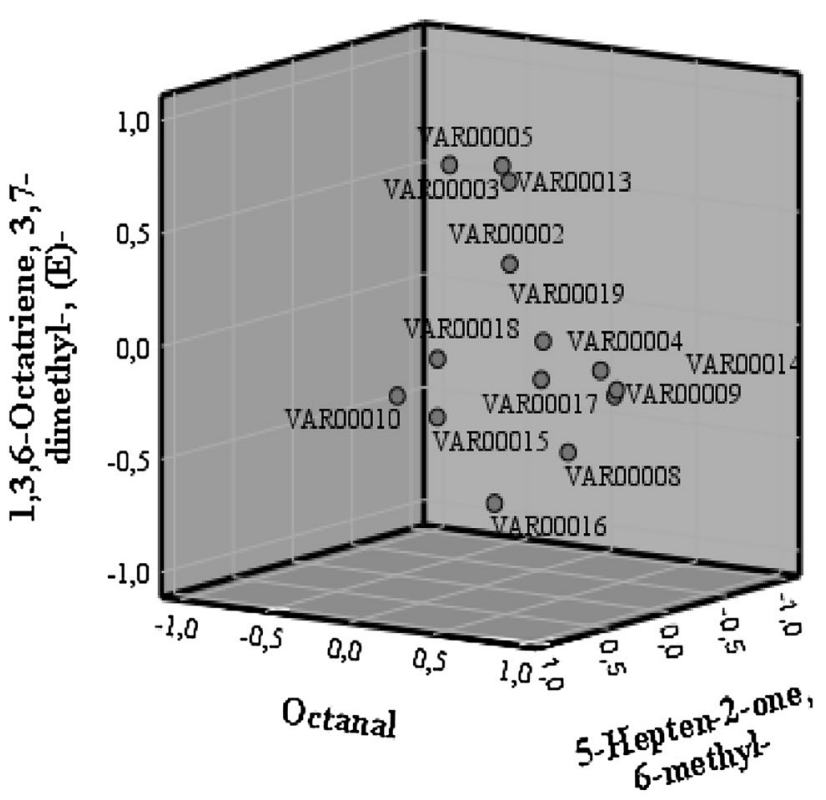

Fig. 2 Volatile compounds of olive oil of the "Ntopia" cultivar from Zakynthos and Kefalonia islands as factor variables (principal components) in the poly-parametric space (three-dimensional display-3D)

$24.880 \%$ of total variance), 1,3,6-octatriene, 3,7-dimethyl-, (E) (PC2, 17.006\% of total variance), 5-hepten2-one, 6-methyl-(PC3, 16.721\% of total variance), and benzene, 1,3-bis(1,1-dimethylethyl) (PC4, $11.665 \%$ of total variance).
Table 2 Volatile compounds identified in olive oil of the "Ntopia" cultivar from Zakynthos and Kefalonia islands as factor variables in the poly-parametric space (Rotated component matrix)

\begin{tabular}{|c|c|c|c|c|}
\hline \multirow[t]{2}{*}{ Volatile compounds } & \multicolumn{4}{|c|}{ Component } \\
\hline & 1 & 2 & 3 & 4 \\
\hline Octanal (VAR00014) & $0.909 *$ & -0.127 & 0.144 & 0.154 \\
\hline Heptanal (VAR00009) & 0.902 & -0.153 & 0.154 & 0.155 \\
\hline Hexanal (VAR00004) & 0.840 & & 0.183 & -0.197 \\
\hline Nonanal (VAR00017) & 0.648 & & 0.413 & 0.418 \\
\hline 1-hexanol (VAR00008) & 0.546 & -0.456 & & 0.241 \\
\hline 1,3,6-octatriene, 3,7-dimethyl-, (E)-(VAR00016) & & $-0.752 *$ & & 0.144 \\
\hline Heptane, 2,4-dimethyl-(VAR00005) & -0.239 & 0.720 & & 0.184 \\
\hline Pentanal (VAR00003) & -0.111 & 0.691 & -0.345 & -0.295 \\
\hline 3-hexen-1-ol, acetate, (Z)-(VAR00013) & & 0.631 & -0.313 & -0.110 \\
\hline 5-hepten-2-one, 6-methyl-(VAR00010) & & -0.144 & 0.802* & \\
\hline Nonane, 2,5-dimethyl-(VAR00015) & 0.279 & -0.223 & 0.761 & \\
\hline Dodecane (VAR00018) & 0.269 & & 0.745 & 0.461 \\
\hline Benzene, 1,3-bis(1,1-dimethylethyl)-(VAR00019) & 0.429 & & & $0.711 *$ \\
\hline 1-propanol (VAR00002) & & 0.309 & -0.114 & -0.664 \\
\hline
\end{tabular}

$V A R$ variable

*Higher correlation (absolute value) 
Table 3 Classification of olive oil samples of the "Ntopia" cultivar from Zakynthos and Kefalonia islands based on volatile compounds and LDA

\begin{tabular}{|c|c|c|c|c|c|}
\hline \multirow{2}{*}{$\begin{array}{l}\text { LDA } \\
\text { Method }\end{array}$} & \multirow[t]{2}{*}{ Classification rate } & \multirow[t]{2}{*}{ Geographical origin } & \multicolumn{2}{|c|}{$\begin{array}{l}\text { Classification of olive } \\
\text { oil samples of the } \\
\text { "Ntopia" cultivar }\end{array}$} & \multirow[t]{2}{*}{ Olive oil samples } \\
\hline & & & Zakynthos & Kefalonia & \\
\hline \multirow[t]{4}{*}{ Original $^{\mathrm{a}}$} & \multirow[t]{2}{*}{ Actual number } & Zakynthos & 33 & 0 & 33 \\
\hline & & Kefalonia & 0 & 31 & 31 \\
\hline & \multirow[t]{2}{*}{$\%$} & Zakynthos & 100.0 & 0.0 & 100.0 \\
\hline & & Kefalonia & 0.0 & 100.0 & 100.0 \\
\hline \multirow[t]{4}{*}{ Cross-validation $^{\mathrm{b}, \mathrm{c}}$} & \multirow[t]{2}{*}{ Actual number } & Zakynthos & 33 & 0 & 33 \\
\hline & & Kefalonia & 0 & 31 & 31 \\
\hline & \multirow[t]{2}{*}{$\%$} & Zakynthos & 100.0 & 0.0 & 100.0 \\
\hline & & Kefalonia & 0.0 & 100.0 & 100.0 \\
\hline
\end{tabular}

${ }^{\mathrm{a}} 100.0 \%$ of original method grouped cases correctly classified

${ }^{\mathrm{b}}$ Cross-validation is done only for those cases in the analysis. In cross-validation method, each case is classified by the functions derived from all cases other than that particular case

${ }^{\mathrm{c}} 100.0 \%$ of cross-validated method grouped cases correctly classified

\section{LDA}

The results of LDA showed that one discriminant function was formed: Wilks' Lambda $=0.122\left(X^{2}=115.916\right.$, $\mathrm{d} f=14, p=0.000)$, given that two geographical regions were examined (Zakynthos and Kefalonia). The discriminant function accounted for $100 \%$ of total variance and had the eigenvalue of 7.228 and canonical correlation 0.937 . The eigenvalue of the discriminant function is an essential parameter in LDA, given that it shows how well
Table 4 Qualitative and quantitative characteristics of MANOVA in relation to the volatile compounds identified in olive oil of the "Ntopia" cultivar from Zakynthos, Kefalonia, Leukada, and Kerkyra islands

\begin{tabular}{llrlll}
\hline Volatile compounds & Wilks' Lambda & \multicolumn{1}{l}{ F } & df1 & df2 & $p$ \\
\hline Ethanol (VAR0001) & 0.919 & 3.910 & 3 & 133 & 0.010 \\
1,3-pentadiene,-(Z) (VAR0002) & 0.771 & 13.191 & 3 & 133 & 0.000 \\
1-propanol (VAR0003) & 0.805 & 10.709 & 3 & 133 & 0.000 \\
Pentanal (VAR0004) & 0.588 & 31.089 & 3 & 133 & 0.000 \\
Toluene (VAR0005) & 0.908 & 4.511 & 3 & 133 & 0.005 \\
Hexanal (VAR0006) & 0.891 & 5.450 & 3 & 133 & 0.001 \\
Heptane, 2,4-dimethyl-(VAR0007) & 0.655 & 23.307 & 3 & 133 & 0.000 \\
(E)-2-hexenal (VAR0008) & 0.811 & 10.342 & 3 & 133 & 0.000 \\
2-hexen-1-ol (VAR0009) & 0.903 & 4.759 & 3 & 133 & 0.003 \\
1-hexanol (VAR00010) & 0.618 & 27.411 & 3 & 133 & 0.000 \\
Heptanal (VAR00011) & 0.761 & 13.912 & 3 & 133 & 0.000 \\
5-hepten-2-one, 6-methyl-(VAR00012) & 0.642 & 24.774 & 3 & 133 & 0.000 \\
Heptane, 2,2,4,6,6-pentamethyl-(VAR00013) & 0.899 & 5.005 & 3 & 133 & 0.003 \\
Decane (VAR00014) & 0.801 & 11.034 & 3 & 133 & 0.000 \\
3-hexen-1-ol, acetate, (Z) (VAR00015) & 0.624 & 26.754 & 3 & 133 & 0.000 \\
Octanal (VAR00016) & 0.744 & 15.268 & 3 & 133 & 0.000 \\
Acetic acid, hexyl ester (VAR00017) & 0.662 & 22.633 & 3 & 133 & 0.000 \\
Nonane, 2,5-dimethyl-(VAR00018) & 0.611 & 28.283 & 3 & 133 & 0.000 \\
Decane, 4-methyl-(VAR00019) & 0.665 & 22.285 & 3 & 133 & 0.000 \\
dl-Limonene (VAR00020) & 0.666 & 22.241 & 3 & 133 & 0.000 \\
1,3,6-octatriene, 3,7-dimethyl-, (E)-(VAR00021) & 0.613 & 27.977 & 3 & 133 & 0.000 \\
Nonanal (VAR00022) & 0.781 & 12.467 & 3 & 133 & 0.000 \\
Dodecane (VAR00023) & 0.817 & 9.956 & 3 & 133 & 0.000 \\
Benzene, 1,3-bis(1,1-dimethylethyl)-(VAR00024) & 0.797 & 11.324 & 3 & 133 & 0.000 \\
\hline & & & & & \\
\hline
\end{tabular}

The variables with higher $F$ value contribute most to the classification process $V A R$ variable, $F$ value of the $F$ function, $d f$ degrees of freedom, $p$ probability 
the function differentiates the initial groups (geographical origin). In parallel, the group centroid values comprise another essential parameter in LDA. The group centroid values are considered for the estimation of the classification ability of the LDA model and refer to the unstandardized canonical discriminant functions, evaluated at group means. The centroid values have two numbers which represent the coordinates (the abscissa is the first discriminant function and the ordinate is the second discriminant function) [51]. Given that only two geographical regions were examined, the group centroid values were: $(2.565$, - 2.300) for Zakynthos and Kefalonia. The classification rate was $100 \%$ using the original and $100 \%$ using the cross-validation method. All olive oil samples of the "Ntopia" cultivar were correctly classified according to geographical origin (Table 3).

Specifying further the analysis, the volatile compounds that contributed most to the discrimination of the geographical origin of the "Ntopia" olive oil samples were those with the highest absolute correlation value within the discriminant function. Therefore, these compounds are considered to be the stronger geographical origin indicators of the olive oil samples of the "Ntopia" cultivar from Zakynthos and Kefalonia. These volatile compounds were: pentanal, 2,4-dimethylheptane, and 1,3,6-octatriene, 3,7-dimethyl-, (E)-(Supplementary Table 8).

\section{Geographical origin discrimination of "Ntopia" olive oil cultivar from Zakynthos, Kefalonia, Leukada, and Kerkyra islands}

Considering the ultimate discrimination results that were obtained for the olive oil samples from Zakynthos and Kefalonia (in total 64 samples of olive oil) the next step was to run the statistical analysis with an additional number of olive oil samples from Leukada (36 samples) and Kerkyra (37 samples) to investigate whether the discrimination model could provide again reliable information for the geographical origin of olive oil of the "Ntopia" cultivar from the 4 Ionian islands.

Table 5 Volatile compounds identified in olive oil of the "Ntopia" cultivar from Zakynthos, Kefalonia, Leukada, and Kerkyra islands as factor variables in the poly-parametric space (Rotated component matrix)

\begin{tabular}{|c|c|c|c|c|c|c|c|}
\hline \multirow[t]{2}{*}{ Volatile compounds } & \multicolumn{7}{|c|}{ Component } \\
\hline & 1 & 2 & 3 & 4 & 5 & 6 & 7 \\
\hline Octanal (VAR00016) & $0.921 *$ & & & & & & \\
\hline Heptanal (VAR00011) & 0.913 & & & & & & \\
\hline Hexanal (VAR0006) & 0.725 & & -0.109 & 0.123 & & 0.366 & \\
\hline 1-Hexanol (VAR00010) & 0.618 & & 0.294 & -0.240 & -0.103 & & 0.209 \\
\hline Nonanal (VAR00022) & 0.613 & 0.428 & & -0.226 & -0.181 & & \\
\hline Nonane, 2,5-dimethyl-(VAR00018) & 0.484 & 0.406 & 0.363 & -0.137 & -0.113 & -0.238 & -0.178 \\
\hline Dodecane (VAR00023) & 0.267 & $0.883 *$ & & -0.160 & & & \\
\hline Decane (VAR00014) & & 0.843 & & & -0.178 & 0.192 & \\
\hline 5-Hepten-2-one, 6-methyl-(VAR00012) & 0.321 & 0.468 & 0.375 & -0.105 & -0.334 & -0.130 & -0.182 \\
\hline Ethanol (VAR0001) & & & $0.750 *$ & 0.158 & & & \\
\hline (E)-2-Hexenal (VAR0008) & & 0.145 & -0.717 & & -0.197 & & \\
\hline Heptane, 2,4-dimethyl-(VAR0007) & -0.334 & 0.398 & -0.403 & 0.204 & & 0.309 & -0.205 \\
\hline 3-Hexen-1-ol, acetate, (Z) (VAR00015) & -0.167 & & & $0.714 *$ & & -0.111 & 0.377 \\
\hline 1-Propanol (VAR0003) & & -0.136 & 0.165 & 0.679 & -0.325 & & \\
\hline Pentanal (VAR0004) & -0.163 & & & 0.647 & 0.369 & -0.180 & \\
\hline 1,3,6-Octatriene, 3,7-dimethyl-, (E)-(VAR00021) & & & 0.442 & -0.521 & -0.242 & 0.184 & 0.199 \\
\hline 1,3-Pentadiene, -(Z) (VAR0002) & & -0.159 & & & $0.707 *$ & -0.101 & -0.120 \\
\hline Acetic acid, hexyl ester (VAR00017) & & -0.172 & & & 0.687 & & \\
\hline Decane, 4-methyl-(VAR00019) & -0.222 & 0.237 & -0.222 & -0.110 & 0.513 & 0.335 & \\
\hline dl-Limonene (VAR00020) & & & -0.231 & -0.178 & -0.174 & $0.629 *$ & \\
\hline Toluene (VAR0005) & & & 0.175 & & & 0.603 & -0.180 \\
\hline 2-Hexen-1-ol (VAR0009) & 0.291 & 0.303 & -0.163 & & & 0.518 & 0.369 \\
\hline Heptane, 2,2,4,6,6-pentamethyl-(VAR00013) & & -0.208 & 0.104 & 0.134 & & -0.121 & $0.805 *$ \\
\hline Benzene, 1,3-bis(1,1-dimethylethyl)-(VAR00024) & 0.354 & 0.450 & & & & -0.148 & 0.615 \\
\hline
\end{tabular}

$V A R$ variable

*Higher correlation (absolute value) 


\section{MANOVA}

Pillai's Trace $=2.213(F=13.118, \mathrm{~d} f=72, p=0.000)$ and Wilks' Lambda $=0.015(F=13.928, \mathrm{~d} f=72, p=0.000)$, showed that there was a significant impact of geographical origin of olive oil samples of the "Ntopia" cultivar on the semi-quantitative data of volatile compounds (composition). The volatile compounds that were determined among the 4 Ionian islands were significant $(p<0.05)$ (Table 4$)$. Thereafter, these volatile compounds were subjected to FA and LDA as follows.

\section{FA}

As in the case of the first part of the study, FA showed that the 24 statistically significant volatile compounds adequately describe the variability in the poly-parametric space. The KMO index was 0.712, while Bartlett's Test of Sphericity index had the values $X^{2}=1403.595, \mathrm{~d} f=276$, $p=0.000$, indicating that there are correlations between the variables that allow the application of factor analysis. The main volatile compounds that showed the highest correlation (factors) are given in bold in Table 5 .

Based on the first 7 principal components (PCs), the variance explained was $65.352 \%$, considered as satisfactory given that the number of samples along with the examined parameters (volatile compounds) was substantially increased (Fig. 3). The volatile compounds for which the correlation value in the rotated component matrix of

\section{Component Plot in Rotated Space}

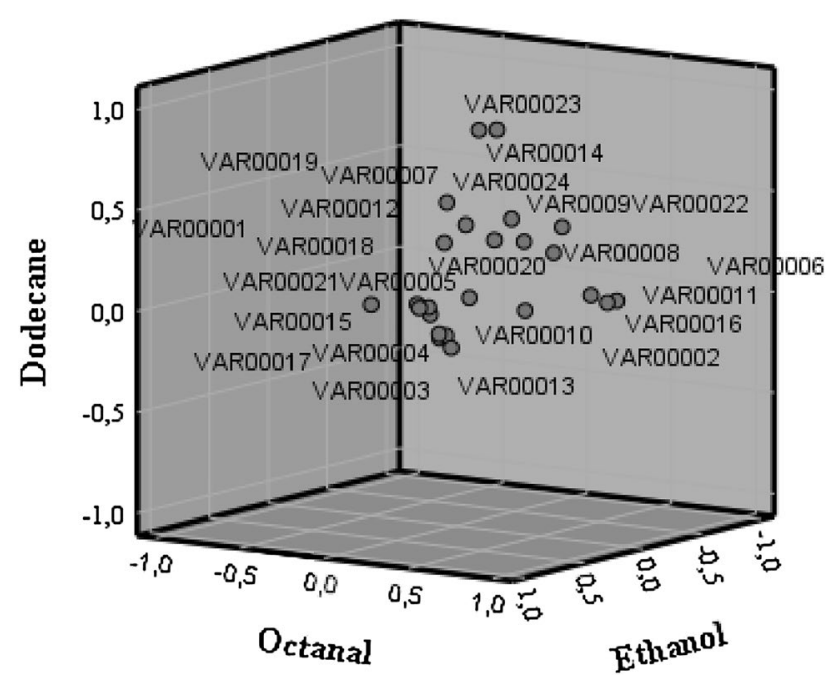

Fig. 3 Volatile compounds of olive oil of the "Ntopia" cultivar from Zakynthos, Kefalonia, Leukada, and Kerkyra islands as factor variables (principal components) in the poly-parametric space (threedimensional display-3D) the poly-parametric space was the largest were: Octanal (PC1, $15.960 \%$ of total variance), dodecane (PC2, $11.463 \%$ of total variance), ethanol (PC3, 8.501\% of total variance), 3-hexen-1-ol, acetate, $(\mathrm{Z})$ (PC4, 8.310\% of total variance), 1,3-pentadiene,-(Z) (PC5, 7.648\% of total variance), dl-limonene (PC6, $6.811 \%$ of total variance) and heptane, 2,2,4,6,6-pentamethyl-(PC7, 6.659\% of total variance) (Table 5).

\section{LDA}

The results of LDA showed that three discriminant functions were formed: Wilks' Lambda $=0.015\left(X^{2}=509.294\right.$, $\mathrm{d} f=72, p=0.000)$ for the first; Wilks' Lambda $=0.092$ $\left(X^{2}=290.717, \mathrm{~d} f=46, p=0.000\right)$ for the second; and Wilks' Lambda $=0.373\left(X^{2}=120.213, \mathrm{~d} f=22, p=0.000\right)$ for the third. The first discriminant function accounted for $51.4 \%$ of total variance and had the highest eigenvalue (4.999) and canonical correlation (0.913). The second discriminant function had a significantly lower eigenvalue (3.045) and canonical correlation $(0.868)$, while accounted for $31.3 \%$ of total variance. Finally, the third discriminant function had the lowest eigenvalue (1.679) and canonical correlation (0.792) accounting for $17.3 \%$ of total variance. All discriminant functions accounted for $100 \%$ of total variance.

In Fig. 4, we can observe that the olive oil samples from Zakynthos and Kerkyra are separated quite satisfactorily in relation to the samples of Leukada and Kefalonia. The classification rate was $95.6 \%$ using the original and $87.6 \%$ using the cross-validation method. The group centroid values were: $(3.901,-0.088),(-1.101,-1.702),(-1.478$, $-1.196)$, (- 1.119, 2.668) for olive oil samples from Zakynthos, Kefalonia, Leukada, and Kerkyra, respectively.

The most encouraging results (based on the cross-validation method) were obtained for the olive oil samples from Kerkyra, where of the 37 initial samples 34 were correctly allocated in Kerkyra (correct prediction rate of 91.9\%), while 2 samples were allocated in Kefalonia and 1 sample in Zakynthos. Similarly, for Zakynthos of the 33 initial samples, 29 were correctly allocated in Zakynthos (correct prediction rate of $87.9 \%$ ), while 3 samples were allocated in Leukada and 1 sample in Kefalonia.

In addition, for the olive oil samples from Leukada, of the 36 initial samples, 31 were correctly allocated in Leukada (correct prediction rate of $86.1 \%$ ), while 3 samples were allocated in Kefalonia and 2 samples in Kerkyra. Finally, for the olive oil samples from Kefalonia of the 31 initial samples, 26 were correctly allocated in Kefalonia (correct prediction rate of $83.9 \%$ ), 3 samples were allocated in Leukada, while 2 samples were allocated in Kerkyra (Table 6).

As mentioned before, specifying further the analysis, the volatile compounds that contributed most to the 
Fig. 4 Geographical origin discrimination of olive oil of the "Ntopia" cultivar from Zakynthos, Kefalonia, Leukada, and Kerkyra islands based on 24 volatile compounds in combination with LDA (twodimensional display-2D). 1: Zakynthos; 2: Kefalonia; 3: Leukada; 4: Kerkyra

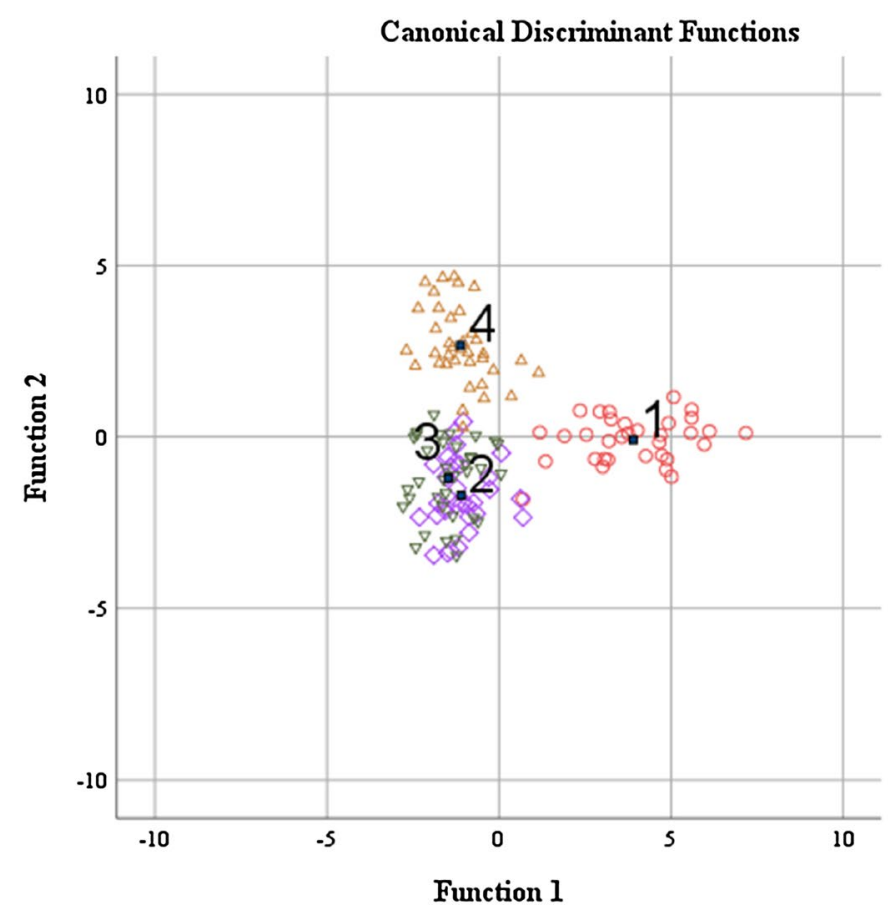

\author{
Geographical \\ origin \\ 1-Zakynthos \\ 2-Kefalonia \\ $\nabla$ 3-Leukada \\ $\triangle$ 4-Kerkyra \\ - Group Centroid
}

Table 6 Classification of olive oil samples of the "Ntopia" cultivar from Zakynthos, Kefalonia, Leukada, and Kerkyra islands based on volatile compounds and LDA

\begin{tabular}{|c|c|c|c|c|c|c|c|}
\hline \multirow{2}{*}{$\begin{array}{l}\text { LDA } \\
\text { Method }\end{array}$} & \multirow[t]{2}{*}{ Classification rate } & \multirow[t]{2}{*}{ Geographical origin } & \multicolumn{4}{|c|}{$\begin{array}{l}\text { Classification of olive oil samples of "Ntopia" } \\
\text { cultivar }\end{array}$} & \multirow[t]{2}{*}{ Olive oil samples } \\
\hline & & & Zakynthos & Kefalonia & Leukada & Kerkyra & \\
\hline \multirow[t]{8}{*}{ Original $^{\mathrm{a}}$} & \multirow[t]{4}{*}{ Actual number } & Zakynthos & 32 & 0 & 1 & 0 & 33 \\
\hline & & Kefalonia & 0 & 28 & 3 & 0 & 31 \\
\hline & & Leukada & 0 & 2 & 34 & 0 & 36 \\
\hline & & Kerkyra & 0 & 0 & 0 & 37 & 37 \\
\hline & \multirow[t]{4}{*}{$\%$} & Zakynthos & 97.0 & 0.0 & 3.0 & 0.0 & 100.0 \\
\hline & & Kefalonia & 0.0 & 90.3 & 9.7 & 0.0 & 100.0 \\
\hline & & Leukada & 0.0 & 5.6 & 94.4 & 0,0 & 100.0 \\
\hline & & Kerkyra & 0.0 & 0.0 & 0.0 & 100.0 & 100.0 \\
\hline \multirow[t]{8}{*}{ Cross-validation $^{\mathrm{b}, \mathrm{c}}$} & \multirow[t]{4}{*}{ Actual number } & Zakynthos & 29 & 1 & 3 & 0 & 33 \\
\hline & & Kefalonia & 0 & 26 & 3 & 2 & 31 \\
\hline & & Leukada & 0 & 3 & 31 & 2 & 36 \\
\hline & & Kerkyra & 1 & 2 & 0 & 34 & 37 \\
\hline & \multirow[t]{4}{*}{$\%$} & Zakynthos & 87.9 & 3.0 & 9.1 & 0.0 & 100.0 \\
\hline & & Kefalonia & 0.0 & 83.9 & 9.7 & 6.5 & 100.0 \\
\hline & & Leukada & 0.0 & 8.3 & 86.1 & 5.6 & 100.0 \\
\hline & & Kerkyra & 2.7 & 5.4 & 0.0 & 91.9 & 100.0 \\
\hline
\end{tabular}

${ }^{\mathrm{a}} 95.6 \%$ of original method grouped cases correctly classified

${ }^{\mathrm{b}}$ Cross-validation is done only for those cases in the analysis. In cross-validation method, each case is classified by the functions derived from all cases other than that particular case

${ }^{\mathrm{c}} 86.7 \%$ of cross-validated method grouped cases correctly classified

discrimination of the geographical origin of the "Ntopia" olive oil samples from the 4 Ionian islands were those with the highest absolute correlation value within the discriminant functions. Therefore, these compounds are considered 
Table 7 Correlation values of volatile compounds identified in olive oil of the "Ntopia" cultivar from Zakynthos, Kefalonia, Leukada, and Kerkyra islands between groups (geographical origin) within each discriminant function

\begin{tabular}{|c|c|c|c|}
\hline \multirow[t]{2}{*}{ Volatile compounds } & \multicolumn{3}{|c|}{ Discriminant function } \\
\hline & 1 & 2 & 3 \\
\hline Nonane, 2,5-dimethyl-(VAR00018) & $0.356 *$ & -0.013 & -0.039 \\
\hline 1-hexanol (VAR00010) & $0.351^{*}$ & -0.013 & -0.038 \\
\hline 1,3,6-octatriene, 3,7-dimethyl-, (E)-(VAR00021) & $0.317^{*}$ & 0.206 & -0.004 \\
\hline 5-Hepten-2-one, 6-methyl-(VAR00012) & $0.316^{*}$ & 0.036 & 0.185 \\
\hline Heptane, 2,4-dimethyl-(VAR0007) & $-0.274^{*}$ & 0.145 & 0.227 \\
\hline Octanal (VAR00016) & $0.262^{*}$ & -0.010 & -0.029 \\
\hline Heptanal (VAR00011) & $0.250 *$ & -0.009 & -0.027 \\
\hline Benzene, 1,3-bis(1,1-dimethylethyl)-(VAR00024) & $0.219 *$ & -0.066 & 0.036 \\
\hline Nonanal (VAR00022) & $0.216^{*}$ & 0.123 & 0.035 \\
\hline Dodecane (VAR00023) & $0.176^{*}$ & 0.138 & 0.084 \\
\hline Ethanol (VAR0001) & $0.115^{*}$ & -0.084 & 0.009 \\
\hline Pentanal (VAR0004) & -0.217 & $-0.390 *$ & -0.044 \\
\hline dl-Limonene (VAR00020) & -0.098 & $0.383^{*}$ & 0.063 \\
\hline 3-hexen-1-ol, acetate, (Z) (VAR00015) & -0.161 & $-0.333^{*}$ & 0.286 \\
\hline Decane (VAR00014) & 0.084 & $\mathbf{0 . 2 2 3}^{*}$ & 0.193 \\
\hline (E)-2-hexenal (VAR0008) & -0.090 & $0.205^{*}$ & 0.196 \\
\hline 2-hexen-1-ol (VAR0009) & 0.029 & $0.178^{*}$ & 0.063 \\
\hline Toluene (VAR0005) & -0.044 & $0.173^{*}$ & 0.029 \\
\hline Heptane, 2,2,4,6,6-pentamethyl-(VAR00013) & 0.085 & $-0.158^{*}$ & 0.026 \\
\hline Hexanal (VAR0006) & 0.097 & $0.156^{*}$ & -0.032 \\
\hline Acetic acid, hexyl ester (VAR00017) & -0.128 & -0.170 & $-0.450^{*}$ \\
\hline 1,3-pentadiene,-(Z) (VAR0002) & -0.098 & -0.130 & $-0.344^{*}$ \\
\hline 1-propanol (VAR0003) & -0.059 & -0.151 & $0.304^{*}$ \\
\hline Decane, 4-methyl-(VAR00019) & -0.194 & 0.239 & $-0.288^{*}$ \\
\hline
\end{tabular}

$V A R$ variable. *Higher correlation (absolute value) to be the stronger geographical origin indicators of the olive oil samples of the "Ntopia" cultivar from Zakynthos, Kefalonia, Leukada, and Kerkyra (Table 7).

The discrimination results presented herein, support and flourish similar studies in the literature concerning the authentication of olive oil, based on volatile compounds analysis and computational statistics, from Albania, Argentina, Australia, California, Brazil, Greece, Italy, Morocco, Peru, Portugal, Spain, and Tunisia [11-13, 26-28].

Based on the data collected from the computational statistics (MANOVA, FA, LDA), the volatile compounds: ethanol, pentanal, 2,4-dimethylheptane, 3,7-dimethyl-1,3,6octatriene (E), 2,5-dimethylnonane, 1-hexanol, 6-methyl-5hepten-2-one, octanal, dl-limonene, acetic acid hexyl ester, and dodecane, could aid to the geographical origin discrimination of "Ntopia" olive oil cultivar when two (Zakynthos and Kefalonia) or four (Zakynthos, Kefalonia, Leukada, and Kerkyra) Ionian islands are subjected to statistical analysis. Considering the aroma notes these compounds possess (Table 1), the study contributes also to the characterization/ definition of the complexity of flavor of the olive oil of the "Ntopia" cultivar from Ionian islands.

\section{Validation of the discrimination results using training and holdout partitions}

To evaluate further the discrimination results obtained after implementation of MANOVA/LDA the semi-quantitative data of the significant volatile compounds were subjected to $\mathrm{KNN}$ analysis. The original sample size ( $N=137$ samples) was randomly divided to a training set (consisting of the 73\% of the original samples, $N=100$ ) and a holdout set (consisting of the $27 \%$ of the original samples, $N=37$ ). All cases were valid during KNN analysis. The overall classification results were in agreement with those of LDA. More specifically, the correct classification rate was $82 \%$ for the training set and $83.8 \%$ for the holdout set (Table 8 ).

\section{Conclusions}

The analysis of volatile compounds of olive oil samples of the "Ntopia" cultivar from Ionian islands proved to be a dynamic tool for the characterization of aroma and 
Table 8 Classification of olive oil samples of the "Ntopia" cultivar from Zakynthos, Kefalonia, Leukada, and Kerkyra islands based on volatile compounds and $\mathrm{KNN}$ analysis

\begin{tabular}{lllllll}
\hline Partition & Observed & Predicted & & & \\
\cline { 3 - 7 } & & Zakynthos & Kefalonia & Leukada & Kerkyra & Percent Correct \\
\hline \multirow{2}{*}{ Training } & Zakynthos & 25 & 0 & 1 & 1 & $92.6 \%$ \\
& Kefalonia & 0 & 19 & 4 & 0 & $82.6 \%$ \\
& Leukada & 0 & 3 & 23 & 0 & $88.5 \%$ \\
& Kerkyra & 1 & 4 & 4 & 15 & $62.5 \%$ \\
& Overall Percent & $26.0 \%$ & $26.0 \%$ & $32.0 \%$ & $16.0 \%$ & $82,0 \%$ \\
Holdout & Zakynthos & 6 & 0 & 0 & 0 & $100,0 \%$ \\
& Kefalonia & 0 & 7 & 1 & 0 & $87.5 \%$ \\
& Leukada & 0 & 1 & 8 & 1 & $80.0 \%$ \\
& Kerkyra & 0 & 3 & 0 & 10 & $76.9 \%$ \\
& Missing & 0 & 0 & 0 & 0 & \\
& Overall Percent & $16.2 \%$ & $29.7 \%$ & $24.3 \%$ & $29.7 \%$ & $83.8 \%$ \\
\hline
\end{tabular}

differentiation of the geographical origin, in which the olive oil was produced, in combination with computational statistics.

Given that the differentiation/determination of the geographical origin of agricultural products is a particularly difficult issue, taking into account the natural/provenance variability, the present results are considered very encouraging, both for the present and for future research. The present study contributes also to the characterization of the aroma of olive oil of a less studied cultivar, that is the "Ntopia" cultivar from Ionian islands. Practical applications of the present study include the authenticity of olive oil from this cultivar, knowledge on volatile composition, and potential financial and other benefits to stakeholders, providing thus, incentives for further accreditation to achieve a possible labeling of the product such as PDO, PGI, or the proposed "Protected Geographical Zone" (PGZ), through consecutive research within the years.

Supplementary Information The online version contains supplementary material available at https://doi.org/10.1007/s00217-021-03863-2.

Acknowledgements The authors are grateful to Assoc. Prof. Anastasia Badeka for the access she provided to the GC/MS unit of the Laboratory of Food Chemistry at the Department of Chemistry of the University of Ioannina.

Funding We acknowledge support of this work by the project "Probing the Bioactive and Health Protective Compounds of Ionian Islands' Olive Oil" (MIS 5005497) which is implemented under the Action "Targeted Actions to Promote Research and Technology in Areas of Regional Specialization and New Competitive Areas in International Level", funded by the Operational Programme "Ionian Islands 20142020" and co-financed by Greece and the European Union (European Regional Development Fund).

\section{Declarations}

Conflict of interest The authors declare that they have no conflict of interest.
Compliance with ethics requirements This study does not contain any studies with human participants or animals performed by any of the authors.

\section{References}

1. Rongai D, Sabatini N, Del Coco L, Perri E, Del Re P, Simone N, Marchegiani D, Fanizzi FP (2017) ${ }^{1} \mathrm{H}$ NMR and multivariate analysis for geographic characterization of commercial extra virgin olive oil: a possible correlation with climate data. Foods 6(11):96. https://doi.org/10.3390/foods6110096

2. Caporaso N (2016) Virgin olive oils: Environmental conditions, agronomical factors and processing technology affecting the chemistry of flavor profile. J Food Chem Nanotechnol 2(1):21-31. https://doi.org/10.17756/jfcn.2016-007

3. United States Department of Agriculture (USDA) (2020) National Agricultural Statistics Service Pacific Regional Office, P.O. Box 1258, Sacramento, CA 95812

4. International Olive Council (IOC) (2020). https://www.internatio naloliveoil.org

5. Galanakis CM, Rizou M, Aldawoud TMS, Ucak I, Rowan NJ (2021) Innovations and technology disruptions in the food sector within the COVID-19 pandemic and post-lockdown era. Trends Food Sci Technol 110:193-200. https://doi.org/10.1016/j.tifs. 2021.02.002

6. Galanakis CM (2020) The food systems in the era of the coronavirus (COVID-19) pandemic crisis. Foods 9(4):523. https://doi. org/10.3390/foods 9040523

7. Galanakis CM, Aldawoud TMS, Rizou M, Rowan NJ, Ibrahim SA (2020) Food ingredients and active compounds against the Coronavirus disease (COVID-19) pandemic: a comprehensive Review. Foods 9(11):1701. https://doi.org/10.3390/foods91117 01

8. Kalua CM, Mailer RJ, Ayton J, Allen MS, Bedgood DR, Bishop AG, Prenzler PD (2006) Discrimination of olive oils and fruits into cultivars and maturity stages based on phenolic and volatile compounds. J Agric Food Chem 54(21):8390-8390. https://doi. org/10.1021/jf068011k

9. European Commission (2009) European Commission 182/2009 of 6 March 2009 amending regulation (EC) no. 1019/2002 on marketing standards for olive oil. Off J Eur Union L63:6-8 
10. Zunin P, Boggia R, Salvadeo P, Evangelisti F (2005) Geographical traceability of West Liguria extra virgin olive oils by the analysis of volatile terpenoid hydrocarbons. J Chrom A 1089(1-2):243249. https://doi.org/10.1016/J.CHROMA.2005.07.005

11. Pizarro C, Rodríguez-Tecedor S, Pérez-del-Notario N, GonzálezSáiz JM (2011) Recognition of volatile compounds as markers in geographical discrimination of Spanish extra virgin olive oils by chemometric analysis of non-specific chromatography volatile profiles. J Chrom A 1218(3):518-523. https://doi.org/10.1016/J. CHROMA.2010.11.045

12. Pouliarekou E, Badeka A, Tasioula-Margari M, Kontakos S, Longobardi F, Kontominas MG (2011) Characterization and classification of Western Greek olive oils according to cultivar and geographical origin based on volatile compounds. J Chrom A 1218(42):7534-7542. https://doi.org/10.1016/J.CHROMA.2011. 07.081

13. Bajoub A, Sánchez-Ortiz A, Ajal EA, Ouazzani N, FernándezGutiérrez A, Beltrán G, Carrasco-Pancorbo A (2015) First comprehensive characterization of volatile profile of north Moroccan olive oils: a geographic discriminant approach. Food Res Int 76:410-417. https://doi.org/10.1016/J.FOODRES.2015.05.043

14. Zhou X, Zhang Q, Chen X, Li X, Han C (2021) In-situ assessment of olive oil adulteration with soybean oil based on thermogravimetric-gas chromatography/mass spectrometry combined with chemometrics. Food Cont 130:108251. https://doi.org/10.1016/j. foodcont.2021.108251

15. Vichi S, Pizzale L, Conte LS, Buxaderas S, López-Tamames E (2003) Solid-phase microextraction in the analysis of virgin olive oil volatile fraction: Modifications induced by oxidation and suitable markers of oxidative status. J Agric Food Chem 51(22):65646571. https://doi.org/10.1021/jf030268k

16. Berlioz B, Cordella C, Cavalli J-F, Lizzani-Cuvelier L, Loiseau A-M, Fernandez X (2006) Comparison of the amounts of volatile compounds in French protected designation of origin virgin olive oils. J Agric Food Chem 54(26):10092-10101. https://doi.org/10. 1021/JF061796+

17. García-González DL, Tena N, Aparicio R (2010) Quality characterization of the new virgin olive oil var. Sikitita by phenols and volatile compounds. J Agric Food Chem 58(14):8357-8364. https://doi.org/10.1021/jf101316d

18. Garrido-Delgado R, Dobao-Prieto MDM, Arce L, Valcárcel M (2015) Determination of volatile compounds by GC-IMS to assign the quality of virgin olive oil. Food Chem 187:572-579. https://doi.org/10.1016/J.FOODCHEM.2015.04.082

19. Conte L, Bendini A, Valli E, Lucci P, Moret S, Maquet A, Lacoste F, Brereton P, García-González DL, Moreda W, Toschi TG (2020) Olive oil quality and authenticity: a review of current EU legislation, standards, relevant methods of analyses, their drawbacks and recommendations for the future. Trends in Food Sci Technol 105:483-493. https://doi.org/10.1016/j.tifs.2019.02.025

20. da Costa JRO, Dal Bosco SM, Ramos RCdS, Machado ICK, Garavaglia J, Villasclaras SS (2020) Determination of volatile compounds responsible for sensory characteristics from Brazilian extra virgin olive oil using HS-SPME/GC-MS direct method. J Food Sci 85(11):3764-3775. https://doi.org/10.1111/1750-3841. 15467

21. Esposto S, Taticchi A, Servili M, Urbani S, Sordini B, Veneziani G, Daidone L, Selvaggini R (2021) Overall quality evolution of extra virgin olive oil exposed to light for 10 months in different containers. Food Chem 351:129297. https://doi.org/10.1016/j. foodchem.2021.129297

22. Dourou A-M, Brizzolara S, Famiani F, Tonuttia P (2021) Changes in volatile organic composition of olive oil extracted from cv. 'Leccino' fruit subjected to ethylene treatments at different ripening stages. J Sci Food Agric 101:3981-3986. https:// doi.org/10.1002/jsfa. 11024
23. Stilo F, Liberto E, Reichenbach SE, Tao Q, Bicchi C, Cordero C (2021) Exploring the extra-virgin olive oil volatilome by adding extra dimensions to comprehensive two-dimensional gas chromatography and time-of-flight mass spectrometry featuring tandem ionization: validation of ripening markers in headspace linearity conditions. J AOAC Inter 104(2):274-287. https://doi. org/10.1093/jaoacint/qsaa095

24. Angerosa F (2002) Influence of volatile compounds on virgin olive oil quality evaluated by analytical approaches and sensor panels. Eur J Lipid Sci Technol 104(9-10):639-660. https://doi. org/10.1002/1438-9312(200210)104:9/10\%3c639::AID-EJLT6 39\%3e3.0.CO;2-U

25. Angerosa F, Servili M, Selvaggini R, Taticchi A, Esposto S, Montedoro G (2004) Volatile compounds in virgin olive oil: occurrence and their relationship with the quality. J Chrom A 1054(1-2):17-31. https://doi.org/10.1016/J.CHROMA.2004.07. 093

26. Kosma I, Badeka A, Vatavali K, Kontakos S, Kontominas M (2016) Differentiation of Greek extra virgin olive oils according to cultivar based on volatile compound analysis and fatty acid composition. Eur J Lipid Sci Technol 118:849-861. https://doi. org/10.1002/ejlt.201500293

27. Cecchi L, Migliorini M, Giambanelli E, Rossetti A, Cane A, Mulinacci N, Melani F (2020) Authentication of the geographical origin of virgin olive oils from the main worldwide producing countries: a new combination of HS-SPME-GC-MS analysis of volatile compounds and chemometrics applied to 1217 samples. Food Cont 112:107156. https://doi.org/10.1016/j.foodcont. 2020.107156

28. Theodosi S, Kosma IS, Badeka AV (2021) Quality characteristics of Koroneiki olive oil from Zakynthos island (Greece) and differentiation depending on the altitude level. Eur Food Res Technol 247:1235-1248. https://doi.org/10.1007/ s00217-021-03705-1

29. Longobardi F, Ventrella A, Casiello G, Sacco D, Tasioula-Margari M, Kiritsakis AK, Kontominas MG (2012) Characterisation of the geographical origin of Western Greek virgin olive oils based on instrumental and multivariate statistical analysis. Food Chem 133:169-175. https://doi.org/10.1016/j.foodchem.2011.09.130

30. Karabagias IK, Badeka A, Casiello G, Longobardi F, Kontominas MG (2019) Rapid screening of olive oil cultivar differentiation based on selected physicochemical parameters, pigment content and fatty acid composition using advanced chemometrics. Eur Food Res Technol 245:2027-2038. https://doi.org/10.1007/ s00217-019-03310-3

31. Kelly S, Heaton K, Hoogewerff J (2005) Tracing the geographical origin of food: the application of multi-element and multi-isotope analysis. Trends Food Sci Technol 16(12):555-567

32. Longobardi F, Ventrella A, Napoli C, Humpfer E, Schütz B, Schäfer H, Kontominas MG, Sacco A (2012) Classification of olive oils according to geographical origin by using ${ }^{1} \mathrm{H}$ NMR fingerprinting combined with multivariate analysis. Food Chem 130:177-183. https://doi.org/10.1016/j.foodchem.2011.06.045

33. Dais P, Hatzakis E (2013) Quality assessment and authentication of virgin olive oil by NMR spectroscopy: a critical review. Anal Chim Acta 765:1-27. https://doi.org/10.1016/j.aca.2012.12.003

34. Gilbert-López B, Valencia-Reyes ZL, Yufra-Picardo VM, GarcíaReyes JF, Ramos-Martos N, Molina-Díaz A (2014) Determination of polyphenols in commercial extra virgin olive oils from different origins (Mediterranean and South American Countries) by liquid chromatography-electrospray time-of-flight mass spectrometry. Food Anal Methods 7:1824-1833. https://doi.org/10. 1007/s12161-014-9825-7

35. Costa J, Mafra I, Oliveira MBPP (2012) Advances in vegetable oil authentication by DNA-based markers. Trends Food Sci Technol 26:43-55. https://doi.org/10.1016/j.tifs.2012.01.009 
36. Conrado JAM, Sequinel R, Dias BC, Silvestre M, Batista AD, da Petruci JFS (2021) Chemical QR code: a simple and disposable paper-based optoelectronic nose for the identification of olive oil odor. Food Chem 350:129243. https://doi.org/10.1016/j.foodc hem.2021.129243

37. Galanakis CM (2015) Separation of functional macromolecules and micromolecules: from ultrafiltration to the border of nanofiltration. Trends Food Sci Technol 42:44-63. https://doi.org/10. 1016/j.tifs.2014.11.005

38. Quintanilla-Casas B, Bustamante J, Guardiola F, García-González DL, Barbieri S, Bendini A, Toschi TG, Vichi S, Tres A (2020) Virgin olive oil volatile fingerprint and chemometrics: towards and instrumental screening tool to grade the sensory quality. LWT-Food Sci Technol 121:108936. https://doi.org/10.1016/j. lwt.2019.108936

39. Cecchi L, Migliorini M, Giambanelli E, Cane A, Mulinacci N, Zanoni B (2021) Volatile profile of two-phase olive pomace (Alperujo) by HS-SPMEGC- MS as a key to defining volatile markers of sensory defects caused by biological phenomena in virgin olive oil. J Agric Food Chem 69:5155-5166. https://doi. org/10.1021/acs.jafc.1c01157

40. McNaught AD, Wilkinson A (1997) IUPAC. Compendium of chemical terminology (the "Gold Book"), 2nd edn. Blackwell, Oxford. https://doi.org/10.1351/goldbook (Online version (2019) created by S. J. Chalk. ISBN 0-9678550-9-8)

41. Huberty CJ, Olejnik S (2006) Applied MANOVA and discriminant analysis, 2nd edn. Wiley, New Jersey

42. Karabagias IK, Karabournioti S, Karabagias VK, Badeka AV (2020) Palynological, physico-chemical and bioactivity parameters determination, of a less common Greek honeydew honey: “ dryomelo." Food Cont 109:106940. https://doi.org/10.1016/j. foodcont.2019.106940

43. Jolliffe IT (2002) Principal component analysis. Springer series in statistics. Springer, New York

44. Field A (2009) Discovering statistics using SPSS, 3rd edn. Sage Publications Ltd., London

45. Ridolfi M, Terenziani S, Patumi M, Fontanazza G (2002) Characterization of the lipoxygenases in some olive cultivars and determination of their role in volatile compounds formation. J Agric Food Chem 50(4):835-839. https://doi.org/10.1021/jf0109118
46. Kalua CM, Allen MS, Bedgood DR, Bishop AG, Prenzler PD, Robards K (2007) Olive oil volatile compounds, flavour development and quality: a critical review. Food Chem 100(1):273-286. https://doi.org/10.1016/j.foodchem.2005.09.059

47. Luna G, Morales MT, Aparicio R (2006) Characterisation of 39 varietal virgin olive oils by their volatile compositions. Food Chem 98(2):243-252. https://doi.org/10.1016/J.FOODCHEM. 2005.05.069

48. Kesen S, Kelebek H, Selli S (2013) Characterization of the volatile, phenolic and antioxidant properties of monovarietal olive oil obtained from cv. Halhali J Am Oil Chem Soc 90:1685-1696. https://doi.org/10.1007/s11746-013-2327-8

49. Fahlbusch K-G, Hammerschmidt F-J, Panten J, Pickenhagen W, Schatkowski D, Bauer K, Garbe D, Surburg H (2002) Flavors and fragrances in Ullmann's encyclopedia of industrial chemistry. Wiley-VCH, Weinheim. https://doi.org/10.1002/14356007.a11_ 141

50. Belitz HD, Grosch W, Schieberle P (2009) Food chemisrty, 4th edn. Springer, Berlin

51. Karabagias IK, Louppis PA, Karabournioti S, Kontakos S, Papastephanou C, Kontominas MG (2017) Characterization and geographical discrimination of commercial Citrus spp. honeys produced in different Mediterranean countries based on minerals, volatile compounds and physicochemical parameters, using chemometrics. Food Chem 217:445-455. https://doi.org/10.1016/j. foodchem.2016.08.124

52. BabushokVI LPJ, Zenkevich IG (2011) Retention indices for frequently reported compounds of plant essential oils. J Phys Chem Ref Data 40(4):43101. https://doi.org/10.1063/1.3653552

53. Malheiro R, Casal S, Rodrigues N, Renard CMGC, Pereira JA (2018) Volatile changes in cv. Verdeal Transmontana olive oil: From the drupe to the table, including storage. Food Res Int 106:374-382. https://doi.org/10.1016/J.FOODRES.2018.01.005

Publisher's Note Springer Nature remains neutral with regard to jurisdictional claims in published maps and institutional affiliations. 